\title{
ANALISIS PENGAWASAN SERTA PENGARUH KAWASAN BERIKAT TERHADAP ARUS KAS, BEBAN PAJAK DAN AKTIVITAS EKSPOR PT.XYZ
}

\author{
Deby Valentina \\ Program Studi Magister Manajemen Universitas Tarumanagara \\ dheby_valentina@yahoo.com
}

\begin{abstract}
Free Trade Area ( FTA ) is a part of globalization. In order to support the economy, Indonesian government provides many facilities in taxation. One of them is through the bonded zone facility. Bonded zone is given to company which using export as their main activities. In this research, the authors want to analyze the supervision of this facility and the influence of the bonded zone toward cash flow, tax expenses and export activity of PT. XYZ. This study used descriptive qualitative method, where the author observed directly in the field through interviews. Primary data used are interview and literatures, documents of PT. XYZ and regulation used as secondary data. This study limits the period of PT. XYZ before accepting the bonded zone facility and afterhand, ie 20162017. The results of this research found that there is still a weakneeses in terms of supervision but the savings in terms of taxation need to be considered. Therefore, the authors analized that this bonded area facility is worth maintaining.
\end{abstract}

Keyword : FTA,taxation, bonded zone, supervision, cash flow, export

\section{PENDAHULUAN}

Pada masa sekarang khususnya di era ekonomi dan era liberalisasi perdagangan, persaingan semakin kompetitif. Perekonomian yang semakin kompetitif ini menuntut lalu lintas perdagangan yang cepat.Ketergantungan terhadap lalu lintas perdagangan internasional dan arus barang semakin dibutuhkan. Negara- negara maju dan berkembangan semakin saling membutuhkan satu sama lain, baik sebagai pangsa pasar produk mereka maupun penghasil bahan baku. Sehingga fenomena impor terus terjadi seiring perkembangan produk dan pasar internasional.

Persaingan ekonomi ini juga dialami oleh perusahaan- perusahaan industri di Indonesia. Salah satunya adalah industri yang bergerak di pengolahan bahan hasil tambang dan mineral logam. Harga mineral yang terus merosot di tahun 2013 sampai dengan 2015 dan perubahan peraturan pemerintah membuat para pengusaha perlu merestruktur rencana jangka panjang mereka. Setelah pemerintah memberlakukan pelarangan ekspor mineral mentah pada awal tahun 2014 lewat Permen ESDM 1/2014 tentang Larangan Ekspor Mineral Mentah ke Luar Negeri, pengusaha banyak yang mengalami kerugian. Bagi pemerintah, tujuan dari penerapan peraturan ini adalah meningkatkan nilai tambah sekaligus menciptakan lapangan pekerjaan.Sebab perusahaan pertambangan diwajibkan membangun pabrik pengolahan atau smelter di dalam negeri. Dengan begitu lapangan pekerjaan akan bertambah bagi masyarakat. 
Tabel 1.1

Perkembangan Realisasi Investasi PMA Berdasarkan Laporan Kegiatan Penanaman Modal (LKPM) Menurut Sektor Tahun 2015-2016 ( Investasi Dalam USD, Juta)

\begin{tabular}{|l|l|l|l|l|l|}
\hline \multirow{2}{*}{ No. } & \multirow{2}{*}{ Sektor } & $\mathbf{2 0 1 5}$ & $\mathbf{2 0 1 6}$ & \\
\cline { 3 - 6 } & & Proyek & Investasi & Proyek & Investasi \\
\hline 1. & Primer & 1934 & 6236.4 & 2312 & 4502 \\
\hline 2. & Sekunder & 7184 & 11763.10 & 9564 & 16687.6 \\
\hline 3. & Tersier & 8620 & 11276.5 & 13451 & 7774.6 \\
\hline & Jumlah & 17738 & 29275.9 & 25238 & 28964.10 \\
\hline
\end{tabular}

Sumber : bkpm.go.id

Dari segi nilai investasi, kegiatan penanaman modal di Indonesia mengalami penurunan pada tahun 2016. Hanya pada sector sekunder dilihat mengalami peningkatan pada tahun 2016.

Memberikan insentif perpajakan merupakan salah satu cara pemerintah Indonesia dalam meningkatkan nilai investasi. Salah satu upaya pemerintah dalam akselerasi ekonomi dan menarik minat investor untuk menanamkan modal di Indonesia adalah melalui pemberian insentif perpajakan berupa pemberian fasilitas Kawasan Berikat.

Tujuan dari penelitian yang dilakukan adalah memperoleh gambaran pengawasan kawasan berikat serta pengaruh pemberian fasilitas ini bagi perusahaan. Dalam jurnal ini, peneliti akan mengobservasi langsung salah satu perusahaan penerima Kawasan Berikat yaitu PT. XYZ

\section{TINJAUAN PUSTAKA}

Pengawasan menurut Siagian $(1989,135)$ adalah " Proses pengamatan daripada pelaksanaan seluruh kegiatan organisasi untuk menjamin agar semua pekerjaan yang sedang dilakukan berjalan sesuai dengan rencana yang telah ditentukan sebelumnya". Pengawasan merupakan salah satu fungsi organisasi dan manajemen. Dikatakan bahwa pengawasan termasuk fungsi organisasi manajemen, karena apabila fungsi ini tidak dilaksanakan, cepat atau lambat akan mengakibatkan matinya/ hancurnya suatu organisasi.Berdasarkan cara pelaksanaannya, pengawasan dapat diklasifikasikan menjadi dua, yaitu pengawasan langsung dan pengawasan tidak langsung. Pengawasan langsung adalah pengawasan yang dilakukan di tempat kegiatan berlangsung, yaitu dengan melakukan inspeksi, verifikasi dan investigasi. Sedangkan pengawasan tidak langsung adalah suatu bentuk pengawasan yang dilakukan dengan mengadakan pemantauan dan pengkajian laporan dan instansi yang sedang diawasi ( Sujamto: 1983,24)

Pajak, menurut teori yang diakui oleh Direktorat Jenderal Pajak, definisi pajak adalah sebagai berikut : “Pajak adalah iuran kepada negara (yang dapat dipaksakan) yang terutang oleh yang wajib membayarnya menurut peraturan dengan tidak mendapat prestasi kembali, yang langsung dapat ditunjuk, dan yang gunanya adalah untuk membiayai pengeluaran- pengeluaran umum berhubung dengan tugas negara menyelenggarakan pemerintahan". Dalam komponen pajak impor ada beberapa pajak yang harus dibayar di antara bea masuk, pajak pertambahan nilai dan pajak penghasilan pasal 22.

Laporan arus kas (statement of cash flows atau cash flow statement) adalah laporan yang menyajikan ikhtisar terinci mengenai semua arus kas masuk dan arus kas keluar, atau sumber dan penggunaan kas selama suatu periode (IAI, 2007). Informasi tentang arus kas suatu perusahaan berguna bagi para pemakai laporan keuangan sebagai dasar untuk menilai kemampuan perusahaan dalam menghasilkan kas dan setara dengan kas.

Kawasan Berikat adalah suatu bangunan, tempat, atau kawasan dengan batas-batas tertentu yang di dalamnya dilakukan kegiatan usaha industri pengolahan barang dan bahan, kegiatan 
rancang bangun, perekayasaan, penyortiran, pemeriksaan awal, pemeriksaan akhir, dan pengepakan atas barang dan bahan asal impor atau barang dan bahan dari dalam Daerah Pabean Indonesia lainnya, yang hasilnya terutama untuk tujuan ekspor. (Peraturan Pemerintah no 33 tahun 1996).

\section{METODOLOGI PENELITIAN}

Jenis penelitian yang digunakan dalam penelitian ini merupakan jenis kualitatif deskriptif. Dikarenakan penelitian ini tidak menitikberatkan padasebuah hasil melainkan pada proses yang terjadi. Oleh karena itu, penelitian kualitatif dapat menggunakan desain penelitian studi kasus.

Permasalahan utama dalam penelitian ini membahas pengawasan serta pengaruh fasilitas kawasan berikat pada PT. XYZ selaku pengguna jasa. Selain itu juga membahas kelemahan serta kelebihan fasilitas ini dalam proses pelaksanaannya sehingga pendekatan yang lebih tepat digunakan adalah pendekatan kualitatif. Periode penelitian ini mengamati kegiatan PT. $\mathrm{XYZ}$ dalam menggunakan fasilitas $\mathrm{KB} / \mathrm{PDKB}$ dengan data yang didapatkan selama tahun 2016-2017. Penulis menggunakan data primer berupa wawancara dengan narasumber serta data sekunder berupa perundang-undangan yang berlaku serta data dari perusahaan terkait.

\section{HASIL DAN PEMBAHASAN}

\section{Pengawasan Fasilitas Kawasan Berikat}

Fungsi pengawasan terhadap pemberian fasilitas Kawasan Berikat dapat dibedakan menjadi pengawasan langsung yang merupakan pengawasan secara fisik dan pengawasan tidak langsung yang merupakan pengawasan terhadap pembukuan perusahaan.

a. Pengawasan yang Bersifat Langsung

Pengawasan langsung, adalah pengawasan yang dilakukan secara pribadi oleh pimpinan atau pengawas dengan mengamati, meneliti, memeriksa, mengecek sendiri secara "on the spot" di tempat pekerjaan, dan menerima laporan-laporan secara langsung pula dari pelaksana. Hal ini dilakukan dengan inspeksi. Mengacu pada teori tersebut, dalam praktiknya PT. XYZ telah menjalankan pengawasan secara langsung terhadap pengelolaan kawasan berikat ini. PT XYZ menjalankan prosedur sesuai PER 35/2013 yaitu petugas bea cukai berada selama 24 jam untuk mengawasi seluruh kegiatan yang berkaitan dengan penggunaan fasilitas kawasan berikat pada perusahaan.

Proses pengawasan dalam hal penggunaan fasilitas Kawasan Berikat oleh PT. XYZ dilakukan ketika PT. XYZ mulai melakukan kegiatan importasi barang hingga saat terjadinya realisasi ekspor dan pada saat dilakukan audit kepabeanan dan cukai. Pertama, pada saat barang yang diimpor tiba. Kedua, pada saat barang yang diimpor diangkut dari pelabuhan bongkar menuju ke Kawasan Berikat. Ketiga, pada saat realisasi ekspor.

\section{b. Pengawasan Tidak Langsung}

Pengawasan tidak langsung dalam penggunaan fasilitas KB/PDKB pada PT.XYZ merupakan pengawasan yang dilakukan terhadap sistem pembukuan yang dibuat oleh perusahaan. Sesuai dengan konsepnya untuk membantu pelaksaan pengurusan pengeluaran barang melalui audit di gudang importir tertentu PT.XYZ harus mempunyai rekam jejak yang baik. Instrumen yang digunakan untuk menjalankan fungsi pengawasan ini berupa post audit. Instrumen tersebut berguna untuk memastikan bahwa PT. XYZ telah mempergunakan fasilitas Kawasan Berikat sesuai dengan ketentuan perundang-undangan di bidang kepabeanan dan cukai agar PT. XYZ dapat mempertanggungjawabkan penggunaan fasilitas tersebut kepada pihak Bea dan Cukai.

\section{Tabel 1.2}


Hasil Pemeriksaan Fasilitas Kawasan Berikat PT. XYZ

\begin{tabular}{|l|l|l|}
\hline No. & $\begin{array}{l}\text { Selisih kurang sediaan bahan baku/ bahan } \\
\text { penolong fasilitas KB }\end{array}$ & Nilai \\
\hline 1. & Bea masuk & Rp 20.241.000 \\
\hline 2. & PPN & $\operatorname{Rp~75.763.000~}$ \\
\hline 3. & PPh Pasal 22 18.941 .000 \\
\hline & Total & $\operatorname{Rp~145.186.000~}$ \\
\hline
\end{tabular}

\section{Sumber : Diolah dari data PT. XYZ}

Dalam tabel di atas diketahui denda yang muncul sebagai hasil dari proses audit yang dilakukan oleh Kantor Wilayah Kantor Bea dan Cukai sebesar Rp 145.186.000,- . Denda ini timbul akibat adanya selisih kuantitas bahan baku yang dicatat dengan data yang diberikan dan dihitung pada saat pemeriksaan lapangan. Oleh sebab itu walaupun pengawasan secara tidak langsung telah dijalankan oleh PT. XYZ, akan tetapi perbaikan harus dilakukan dalam pencatatan bahan baku yang masuk harus secara akurat dan PT. XYZ juga perlu melakukan stok opname berkala secara internal.

\section{Pengelolaan Kawasan Berikat Terhadap Arus Barang PT. XYZ}

Analisis mengenai kelancaran proses pemasukan dan pengeluaran barang bagi perusahaan penerima fasilitas $\mathrm{KB} / \mathrm{PDKB}$ tidak bisa digambarkan secara kuantitatif, tetapi hanya bisa secara kualitatif dengan ukuran atau tingkatan yang bersifat relative. Berikut data kelancaran arus barang PT. XYZ menurut observasi penulis di lapangan serta keterangan narasumber:

Tabel 5.2

Data Kelancaran Arus Barang PT. XYZ

\begin{tabular}{|c|c|c|c|c|c|}
\hline No. & $\begin{array}{l}\text { Uraian Aktivitas Pemasukan atau } \\
\text { Pengeluaran Barang }\end{array}$ & $\begin{array}{l}\text { Lebih } \\
\text { Baik }\end{array}$ & Sama & $\begin{array}{l}\text { Lebih } \\
\text { Buruk }\end{array}$ & Kesimpulan \\
\hline 1. & $\begin{array}{l}\text { Pemasukan barang impor berupa } \\
\text { bahan baku }\end{array}$ & $\mathrm{X}$ & & & $\mathrm{B}$ \\
\hline 2. & $\begin{array}{l}\text { Pemasukan barang impor berupa } \\
\text { bahan penolong }\end{array}$ & $\mathrm{X}$ & & & B \\
\hline 3. & $\begin{array}{l}\text { Pemasukan barang impor berupa } \\
\text { suku cadang dan peralatan pabrik }\end{array}$ & $\mathrm{X}$ & & & $\mathrm{B}$ \\
\hline 4. & $\begin{array}{l}\text { Pemasukan barang local berupa } \\
\text { bahan baku }\end{array}$ & & $\mathrm{X}$ & & $\mathrm{N}$ \\
\hline 5. & $\begin{array}{l}\text { Pemasukan barang lokal berupa } \\
\text { bahan penolong }\end{array}$ & & $\mathrm{X}$ & & $\mathrm{N}$ \\
\hline 6. & $\begin{array}{l}\text { Pemasukan barang impor berupa } \\
\text { suku cadang dan peralatan pabrik }\end{array}$ & & $\mathrm{X}$ & & $\mathrm{N}$ \\
\hline 7. & $\begin{array}{l}\text { Pembelian barang yang melibatkan } \\
\text { pihak ketiga }\end{array}$ & $\mathrm{X}$ & & & B \\
\hline 8. & $\begin{array}{l}\text { Pinjam meminjam barang dengan } \\
\text { pihak ketiga atau pelanggan }\end{array}$ & & $\mathrm{X}$ & & $\mathrm{N}$ \\
\hline 9. & Penjualan ke luar negeri (ekspor ) & & & $\mathrm{X}$ & $\mathrm{J}$ \\
\hline 10. & $\begin{array}{l}\text { Penjualan ke KB/PDBKB/PDKB } \\
\text { Lainnya }\end{array}$ & & $\mathrm{X}$ & & $\mathrm{N}$ \\
\hline
\end{tabular}

Sumber : Diolah dari hasil pengamatan operasional PT. XYZ 


$\begin{array}{cc}\text { Keterangan } & : \mathrm{B}, \text { Kondisinya lebih baik } \\ \mathrm{N}, \text { kondisinya normal, hamper sama saja } \\ \mathrm{J}, \text { kondisinya lebih buruk }\end{array}$

Dari data tersebut, memberikan gambaran bahwa untuk kegiatan impor barang berjalan lebih aktif dan baik sejak PT.XYZ menerima fasilitas KB/PDKB. Sedangkan, untuk aktivitas yang lain berjalan normal, dan yang perlu diperhatikan adalah terhadap aktivitas ekspor PT.XYZ yang diharapkan meningkat tetapi menjadi lebih buruk. Untuk mengetahui nilai tambah dari penilaian "Lebih Baik" dan resiko dari penilaian "Lebih Buruk" perlu dilihat, dari tingkat frekuensi atau intensitas dalam operasional perusahaan dan seberapa besar manfaat atau resiko yang ada .

Pengaruh Fasilitas Kawasan Berikat Terhadap Arus Kas/ Cash Flow Perusahaan Data pengurangan Arus Kas Keluar PT. XYZ Periode 2016 dan 2017

\section{Tabel 5.3}

Statement of Cash Flow

\begin{tabular}{|l|l|l|}
\hline $\begin{array}{l}\text { Arus Kas dari Aktivitas } \\
\text { Operasional }\end{array}$ & $\mathbf{2 0 1 6}$ & $\mathbf{2 0 1 7}$ \\
\hline Net income & $(237.105 .940 .150,70)$ & $(107.105 .148 .222,65)$ \\
\hline Depreciation expenses & $49.811 .540 .350,80$ & $41.241 .525 .456,79$ \\
\hline Total (increase) in & $(187.294 .399 .799,90)$ & $(65.863 .622 .765,86)$ \\
\hline $\begin{array}{l}\text { Decrease } \\
\text { prepaid taxes }\end{array}$ & $16.923 .055 .766,01$ \\
\hline
\end{tabular}

\section{Sumber : Diolah dari data PT. XYZ}

Dari data tersebut di atas, dengan mendapatkan fasilitas KB/PDKB, PT.XYZ dapat mengurangi beban arus kas sebesar Rp 34.301.346.247,33 pada tahun 2017 jika dibandingkan pada tahun 2016, pada prepaid taxes. Walaupun nilai tersebut di atas bukan merupakan nilai yang dinikmati dalam bentuk cash ( lancar), namun jumlahnya secara efektif berpengaruh dalam pengelolaan kas perusahaan.

\section{KESIMPULAN DAN SARAN}

\section{Kesimpulan}

Beberapa kesimpulan mengenai penggunaan Kawasan Berikat yang dilakukan dalam rangkapenghematan pajak, yakni :

1. $\quad$ PT XYZ telah menjalankan pengawasan secara langsung dan tidak langsung. Dari hasil penelitian penulis, pengawasan belum secara optimal dikarenakan hambatanhambatan yang terjadi di lapangan terutama dari segi SDM dan integritas pegawai serta petugas lapangan yang bertanggung jawabPT. XYZ melakukan penghematan yang cukup besar pada saat menerima fasilitas kawasan berikat, sehingga berpengaruh cukup baik pada arus kas perusahaan.

2. Menimbang berbagai kelemahan dan keunggulan dari prosedur kawasan berikat yang diterima oleh PT. XYZ, penulis berpendapat bahwa fasilitas kawasan berikat pada PT. XYZ masih layak diimplementasikan terhadap kegiatan ekspor- impor perusahaan dengan menganalisa manfaat yang diterima dari segi perpajakan.

\section{Saran}

Berdasarkan dari penelitian yang telah dilakukan, terdapat beberapa rekomendasi saran sebagai masukan dan bahan pertimbangan bagi perusahaan PT XYZ: 
1. Peningkatan pengawasan secara langsung maupun tidak langsung pada PT. XYZ. Pengawasan secara langsung dapat melalui petugas pabean yang bertugas di lapangan. Pengawasan langsung oleh supervisi ekspor impor serta bagian keuangan secara periodik ke lapangan untuk menghindari resiko fraud yang terjadi dalam implementasi kawasan berikat ini. PT XYZ juga perlu memberikan pelatihan- pelatihan khusus ahli kepabeanan kepada staff ekspor impor yang bertugas sehingga dapat memperoleh pengetahun lebih mendalam.

2. Meningkatkan volume ekspor lewat penambahan mesin dan peralatan pabrik dan perluasan areal kawasan berikat. Penambahan mesin dan peralatan pabrik penunjang produksi membutuhkan lahan yang luas, oleh sebab itu penulis menyarankan agar areal KB PT XYZ diajukan perluasan sehingga PT XYZ dapat menjalankan kegiatan pengolahan secara maksimal.

\section{DAFTAR PUSTAKA}

\section{BUKU}

Arens, A. A. (1991). Auditing. New Jersey: Prentice Hall Inc.

Babbie, E. (1995). The Practical of Social Research 8 ed. California: Wadsworth.

Ismail, T. (2004). Menyibak Fenomena Perpajakan di Belahan Dunia . Jakarta: Yarsif Watampone.

Lumbantoruan, S. (1987). Ensiklopedia Perpajakan Indonesia. Jakarta: Erlangga.

Lumbantoruan, S. (1987). Ensiklopedia Perpajakan Indonesia. Jakarta: Erlangga.

Mansury, R. (1999). Kebijakan Fiskal. Jakarta: Yayasan Pengembangan dan Penyebaran Pengetahuan Perpajakan.

Mulyadi. (2002). Auditing. Buku 2. Jakarta: Salemba Empat.

Nasution, S. (2003). Metode Research ( Penelitian Ilmiah ). Jakarta: PT Bumi Aksara.

Neuman, W., \& Lawrence. (1994). Social Research Methods: Qualitative and Quantitative Approach. London: Sage Publications.

Prastowo, A. (2011). Metode Penelitian Kualitatif dalam Perspektif Rancangan Penelitian. Jogjakarta: Ar-Ruzz Media.

Purwito, M., \& Ali. (2006). Kepabeanan Konsep dan Aplikasi. Jakarta: Samudra Ilmu.

Rahardja, P., \& Mandala, M. (2004). Teori Ekonomi Makro : Suatu Pengantar, Edisi Kedua. Jakarta: Lembaga Peneribit Fakultas Ekonomi Universitas Indonesia .

Sudikin, B. d. (2002). Metode Penelitian Kualitatif Perspektif Mikro. Surabaya: Ihsan Cendikia.

Tim Penyusunan Modal Pusdiklat Bea dan Cukai. (2011). Pengantar Audit Kepabeanan dan Cukai. Jakarta: BPPK Pusdiklat Bea dan Cukai.

\section{Wawancara}

Lucia. Wawancara mendalam. 3 Mei 2018

Daswandi. Wawancara mendalam. 12 Mei 2018

Kasubsi Hanggar Lapangan. Wawancara mendalam. 10 Mei 2018

\section{Internet}

www.kemendag.go.id

www.pajak.go.id

www.bkpm.go.id

www.beacukai.go.id 


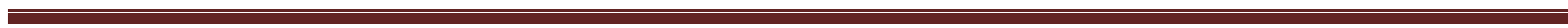
$\cdot$ 